\title{
Taltirelin is a superagonist at the human thyrotropin-releasing hormone receptor
}

\author{
Nanthakumar Thirunarayanan, Bruce M. Raaka and Marvin C. Gershengorn* \\ Laboratory of Endocrinology and Receptor Biology, National Institute of Diabetes and Digestive and Kidney Diseases, National Institutes \\ of Health, Bethesda, MD, USA
}

\section{Edited by:}

Hubert Vaudry, University of Rouen,

France

Reviewed by:

Hubert Vaudry, University of Rouen,

France

Ludovic Galas, Institut National de la

Santé et de la Recherche Biomédicale,

France

\section{${ }^{*}$ Correspondence:}

Marvin C. Gershengorn, Laboratory of

Endocrinology and Receptor Biology,

National Institute of Diabetes and

Digestive and Kidney Diseases,

National Institutes of Health,

50 South Drive, Room 4134,

Bethesda, MD 20892, USA.

e-mail: marving@intra.niddk.hih.gov
Taltirelin (TAL) is a thyrotropin-releasing hormone (TRH) analog that is approved for use in humans in Japan. In this study, we characterizedTAL binding to and signaling by the human $\mathrm{TRH}$ receptor (TRH-R) in a model cell system. We found that TAL exhibited lower binding affinities than TRH and lower signaling potency via the inositol-1,4,5-trisphosphate/calcium pathway than TRH. However, TAL exhibited higher intrinsic efficacy than TRH in stimulating inositol-1,4,5-trisphosphate second messenger generation. This is the first study that elucidates the pharmacology of TAL at TRH-R and shows that TAL is a superagonist at TRH-R. We suggest the superagonism exhibited by TAL may in part explain its higher activity in mediating central nervous system effects in humans compared to TRH.

Keywords: taltirelin, thyrotropin-releasing hormone, human TRH receptor

\section{INTRODUCTION}

Based on evidence that thyrotropin-releasing hormone (TRH) modulates a number of central nervous system (CNS) activities including arousal, antidepressant activity, anxiolytic effects, increase in locomotor activity, antagonism of pentobarbitalinduced sedation, thermoregulation, and cardiovascular and gastrointestinal autonomic functions (Horita et al., 1986; Horita, 1998; Khomane et al., 2011), many analogs of TRH were synthesized and studied. Taltirelin (TAL) hydrate [(1-methyl-(S)-4,5dihydroorotyl)-histidyl-prolinamide, TA-0910] is an analog that showed improved CNS activity (Suzuki et al., 1990; Yamamura et al., 1991, 1997) and lower thyrotropin (TSH)-releasing activity (Yamamura et al., 1997) compared to TRH in rodents. Based on these characteristics, TAL was studied as a treatment for neurodegenerative disorders and is the only TRH analog that has been approved for use in humans; it is used in Japan to treat patients with adult spinal muscular atrophy (Ceredist $\left.{ }^{\circledR}\right)$.

In some mammals, including rodents, there are two subtypes of $\mathrm{G}$ protein-coupled (or seven-transmembrane-spanning) receptors for TRH. These are TRH receptor 1 (TRH-R1), which is the primary (or only) receptor in TSH-secreting cells, and TRHR2, which is expressed throughout the CNS along with TRH-R1 but typically in different areas of the brain (O'Dowd et al., 2000; Sun et al., 2003). In humans, by contrast, only a single type of receptor for TRH, TRH-R, is expressed that is more similar to TRH-R1 than TRH-R2 (Duthie et al., 1993; Matre et al., 1993). It has been reported that TAL binds with lower affinity than TRH to receptors in rat or mouse pituitary and in brain tissue preparations (Kinoshita et al., 1997; Asai et al., 1999, 2005). However, the pharmacology of TAL at TRH-R has not been characterized.
In this study, we characterized TAL binding and signaling by TRH-R in a model cell system and show that TAL is a superagonist at TRH-R.

\section{MATERIALS AND METHODS MATERIALS}

Dulbecco's modified Eagle's medium (DMEM) and fetal bovine serum were purchased from Biosource (Rockville, MD, USA). TRH (pyroGlu-His-ProNH ${ }_{2}$ ) and MeTRH (pGlu-His $(1(\tau)$ methyl)-ProNH ${ }_{2}$ ) were purchased from Sigma (St. Louis, MO, USA). $\left.{ }^{3} \mathrm{H}\right] \mathrm{MeTRH}$ was purchased from PerkinElmer (Waltham, MA, USA). TAL (N-[[(4S)-Hexahydro-1-methyl-2,6-dioxo-4pyrimidinyl]carbonyl]-L-histidyl-L-prolinamide) was obtained from Tocris (San Diego, CA, USA).

\section{CELL CULTURE AND GENERATION OF CELLS STABLY EXPRESSING TRH-R}

HEK-EM 293 (human embryonic kidney) cells stably expressing TRH-R were generated as follows. The human TRH-R cDNA in pcDNA3.1(+) was obtained from the Missouri S\&T cDNA Resource Center (Rolla, MO, USA) and was subcloned into the pcDNA3.1(+)/hygromycin vector. HEK-EM 293 cells were transfected with the cDNA of TRH-R using FuGENE 6 transfection reagent (Roche Diagnostics GmbH, Mannheim, Germany) and the cell clones stably expressing TRH-R were selected using hygromycin $(250 \mu \mathrm{g} / \mathrm{ml})$. HEK-EM 293 cells stably expressing TRH-R were grown in DMEM containing $10 \%$ fetal bovine serum, $100 \mathrm{U} / \mathrm{ml}$ penicillin, $10 \mu \mathrm{g} / \mathrm{ml}$ streptomycin, and $200 \mu \mathrm{g} / \mathrm{ml}$ hygromycin B (Invitrogen, Carlsbad, CA, USA) at $37^{\circ} \mathrm{C}$ in a humidified $5 \% \mathrm{CO}_{2}$ incubator. 


\section{COMPETITION BINDING}

Competition binding assays were performed in monolayers of intact HEK cells expressing TRH-Rs. The cells (220,000 cells/well in 24-well plates) were preincubated with various concentrations of unlabeled TAL, TRH, or MeTRH for $15 \mathrm{~min}$ before addition of radioligand and then incubated at $37^{\circ} \mathrm{C}$ for $1 \mathrm{~h}$ with $4 \mathrm{nM}\left[{ }^{3} \mathrm{H}\right] \mathrm{MeTRH}$ as described elsewhere (Engel et al., 2006). Non-specific binding was determined in incubations with excess non-radiolabeled MeTRH. $\mathrm{IC}_{50}$ is the concentration of unlabeled ligand that reduces specific binding of $\left[{ }^{3} \mathrm{H}\right] \mathrm{MeTRH}$ by $50 \%$. The receptor number per cell was calculated from competition binding curves of various doses of unlabeled MeTRH and $4 \mathrm{nM}$ $\left[{ }^{3} \mathrm{H}\right] \mathrm{MeTRH}$ (Figure 1) and found to be 16,000/cell.

\section{MEASUREMENT OF INTRACELLULAR CALCIUM MOBILIZATION}

Cells stably expressing TRH-R were seeded in black-walled, clearbottomed 96-well plates (Corning, NY, USA) at a density of 60,000 cells/well in DMEM with 10\% fetal bovine serum and incubated for $24 \mathrm{~h}$ at $37^{\circ} \mathrm{C}$ in $5 \% \mathrm{CO}_{2}$. The following day, the culture media was replaced with $100 \mu \mathrm{l}$ of Hank's balanced salt solution with $20 \mathrm{mM}$ HEPES, pH 7.5 and the cells were loaded with $100 \mu \mathrm{l}$ of calcium 4 fluorescent dye (Molecular Devices, Sunnyvale, CA, USA) for $1 \mathrm{~h}$ at room temperature before addition of compounds. Transient changes in intracellular $\left[\mathrm{Ca}^{++}\right]$induced by TAL, TRH, or MeTRH were measured using the FLIPR ${ }^{\text {TETRA }}$ system (Molecular Devices, Sunnyvale, CA, USA). Changes in fluorescence were detected at the emission wavelength ranges from 515 to $575 \mathrm{~nm}$. The agonistic responses of ligands were assessed

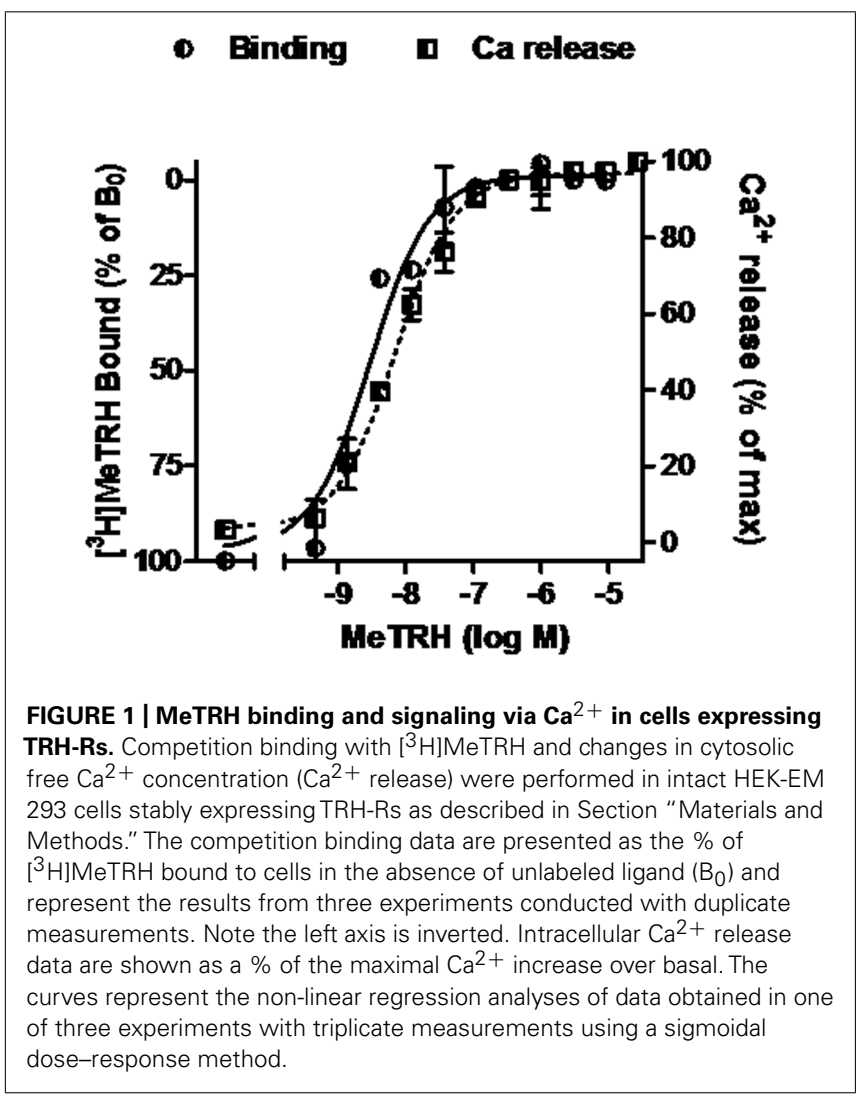

immediately upon their addition in a concentration range from $0.1 \mathrm{nM}$ to $30 \mu \mathrm{M}$. Responses were measured as peak fluorescent intensity minus basal fluorescent intensity at each compound concentration and are presented as \% of the maximum response.

\section{MEASUREMENT OF IP1 PRODUCTION}

Cells were seeded at 220,000/well in white, solid bottom, tissue culture-treated 24 -well plates and cultured at $37^{\circ} \mathrm{C}$ with $5 \% \mathrm{CO}_{2}$ overnight. Serial dilutions of TAL, TRH, or MeTRH, in Hank's balanced salt solution with $20 \mathrm{mM}$ HEPES and $50 \mathrm{mM} \mathrm{LiCl}, \mathrm{pH}$ 7.4 , were added at $200 \mu \mathrm{l} /$ well on the second day. After $60 \mathrm{~min}$ incubation at $37^{\circ} \mathrm{C}$ in $5 \% \mathrm{CO}_{2}$, inositol monophosphate (IP1) content was measured using the IP-One ELISA kit (Cisbio International, France) according to the manufacturer's protocol. The results were calculated as IP1 nanomoles/well and are presented as $\%$ of the maximum response.

\section{DATA ANALYSIS}

The dose-response data were analyzed by non-linear regression of curve fit with one-site competition using GraphPad Prism software version 4 (GraphPad, Inc., San Diego, CA, USA) and the significance was determined by $t$-test or ANOVA.

\section{RESULTS}

The pharmacology of TAL binding and signaling was studied in HEK-EM 293 cells, which do not endogenously express TRH-Rs, engineered to express 16,000 TRH-Rs/cell (Table 1). In competition binding assays using $4 \mathrm{nM}\left[{ }^{3} \mathrm{H}\right] \mathrm{MeTRH}$ and various doses of unlabeled MeTRH, the concentration of MeTRH that halfmaximally inhibited $\left[{ }^{3} \mathrm{H}\right] \mathrm{MeTRH}$ binding $\left(\mathrm{IC}_{50}\right)$ was $3.0 \mathrm{nM}$ (Figure 1). The half-maximally effective concentration $\left(\mathrm{EC}_{50}\right)$ of MeTRH for stimulating an increase in cytosolic $\mathrm{Ca}^{2+}$ concentration $\left(\mathrm{Ca}^{2+}\right.$ release) was $7.2 \mathrm{nM}$, which is not different from the $\mathrm{IC}_{50}(p>0.1)$. Thus, MeTRH is an agonist at TRH-R with high potency. We compared the effects of TAL and TRH in competing for $\left[{ }^{3} \mathrm{H}\right] \mathrm{MeTRH}$ binding and on stimulating $\mathrm{Ca}^{2+}$ release (Figure 2). The $\mathrm{IC}_{50}$ values were 910 and $36 \mathrm{nM}$ for TAL and TRH, respectively, and the $\mathrm{EC}_{50}$ values were 36 and $5.0 \mathrm{nM}$ for TAL and $\mathrm{TRH}$, respectively. Thus, TRH was a high potency agonist and TAL was a moderate potency agonist at TRH-R. We noted, moreover, that the $\mathrm{IC}_{50} / \mathrm{EC}_{50}$ ratio was 25 for TAL $(p<0.02), 7.2$ for TRH $(p<0.05)$, and approximately 0.4 for MeTRH. When comparing two agonists, the agonist with the higher $\mathrm{IC}_{50} / \mathrm{EC}_{50}$ ratio has a greater intrinsic efficacy (Engel et al., 2006). These findings suggested that TAL may be a more efficacious agonist than TRH and that TRH is more efficacious than MeTRH. We previously showed that TRH exhibited a higher intrinsic efficacy than MeTRH at

Table 1 | Pharmacological parameters for TRH-R.

\begin{tabular}{lll}
\hline & $\begin{array}{l}\mathbf{I C}_{\mathbf{5 0}} \text { for binding } \\
\text { (nM) }\end{array}$ & $\begin{array}{l}\mathbf{E C}_{\mathbf{5 0}} \text { for Ca signaling } \\
\text { (nM) }\end{array}$ \\
\hline MeTRH & 3.0 & 7.2 \\
TAL & 910 & 36 \\
TRH & 36 & 5.0
\end{tabular}




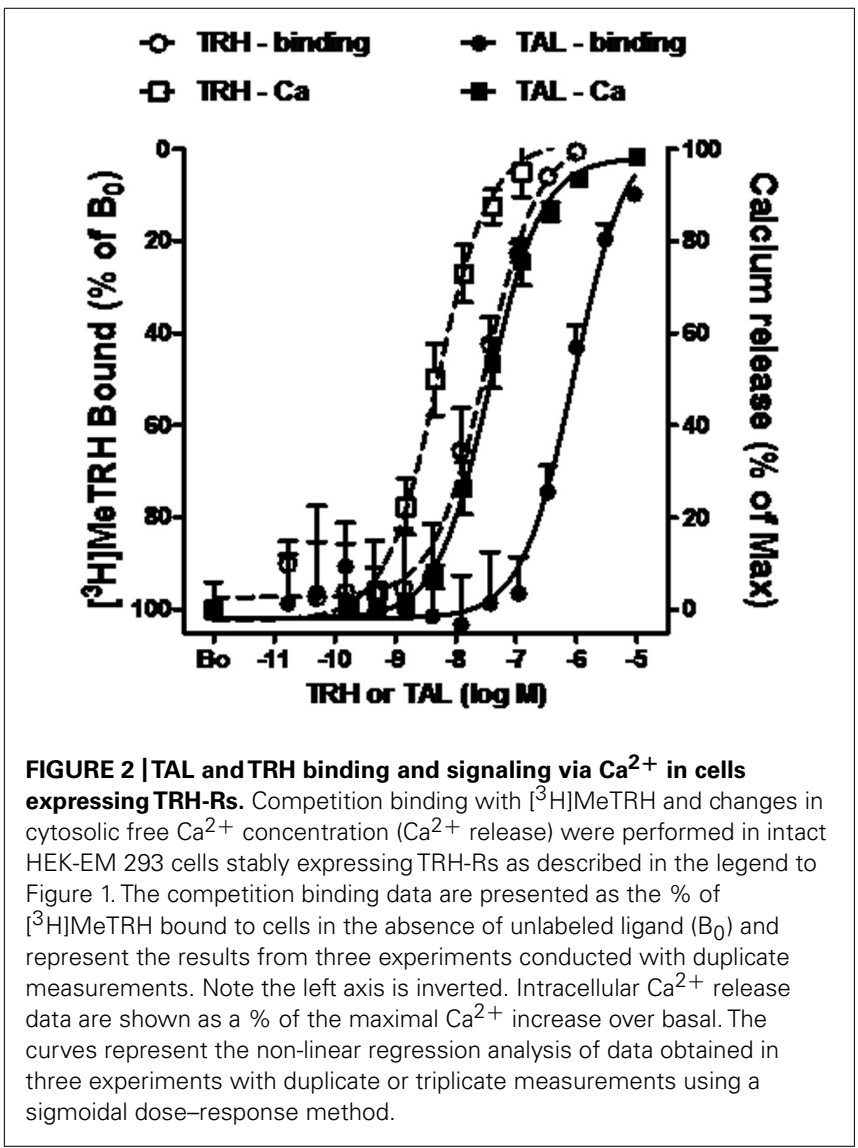

mouse TRH-Rs (Engel et al., 2006). As TRH is the natural, full agonist, TAL is termed a superagonist, and MeTRH is a partial agonist.

As $\mathrm{Ca}^{2+}$ release is a rapid and transient response to TRH- $\mathrm{R}$ activation, it is easier to compare relative intrinsic efficacies by quantifying activation of the inositol-1,4,5-trisphosphate pathway. Inositol-1,4,5-trisphosphate production is the step prior to $\mathrm{Ca}^{2+}$ release in signal transduction by TRH-Rs (Gershengorn, 1986) and can be quantified by measuring accumulation of its metabolic product IP1 over time by inhibiting IP1 degradation (Figure 3A). The $\mathrm{EC}_{50}$ values for IP1 production were found to be $150 \mathrm{nM}$ for TAL and $3.9 \mathrm{nM}$ for TRH. More importantly, TAL was clearly more efficacious than TRH in that TAL stimulated an increase in IP1 production that was $180 \%$ of that stimulated by TRH $(p<0.001)$.

Another way of demonstrating relative intrinsic efficacies of agonists is to show that the maximal response of a more efficacious agonist is inhibited by a less efficacious agonist (Engel et al., 2006). Figure 3B illustrates the IP1 responses to maximally effective doses of MeTRH, TRH, and TAL. As is evident, TAL (3.5fold over MeTRH) is more efficacious than TRH (2.1-fold over MeTRH); MeTRH is the least efficacious. As predicted, the least efficacious agonist MeTRH inhibited the response to TRH (full agonist) and to TAL (superagonist).

\section{DISCUSSION}

In this study, we characterized the binding and signaling properties of TAL at TRH-R that, to our knowledge, have not been previously reported. The binding properties of TAL at rodent TRH receptors have been studied previously (Asai et al., 1999; Brown, 1999). In agreement with the findings with rodent receptors, we found that TAL binds to TRH-R with lower affinity than TRH. Our most interesting observation, however, is that TAL exhibits higher intrinsic efficacy than TRH; that is, TAL can stimulate the same level of signaling as TRH but at lower levels of receptor occupancy and could induce higher levels of signaling than TRH at full occupancy (Figure 3). Since TRH is the natural, full agonist for TRH-R, TAL is termed a superagonist. We previously reported that other TRH analogs displayed higher intrinsic efficacies than TRH at rodent TRH receptors (Engel et al., 2006). In the same study, we showed that MeTRH, the only TRH analog with higher affinity and potency than TRH, was a partial agonist that displayed lower intrinsic efficacy than TRH and that when high levels of TRH and MeTRH were added simultaneously the level of signaling was lowered to that of MeTRH. This is the predicted effect of adding a

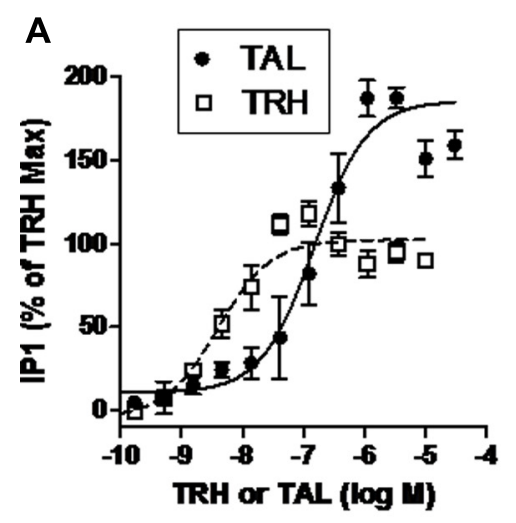

FIGURE 3 |TAL is a superagonist at TRH-R. (A) IP1 production was determined in HEK 293 cells expressing TRH-R in the presence of increasing doses of TAL or TRH as described in Section "Materials and Methods." The data represent the mean of duplicate points from five experiments.
B

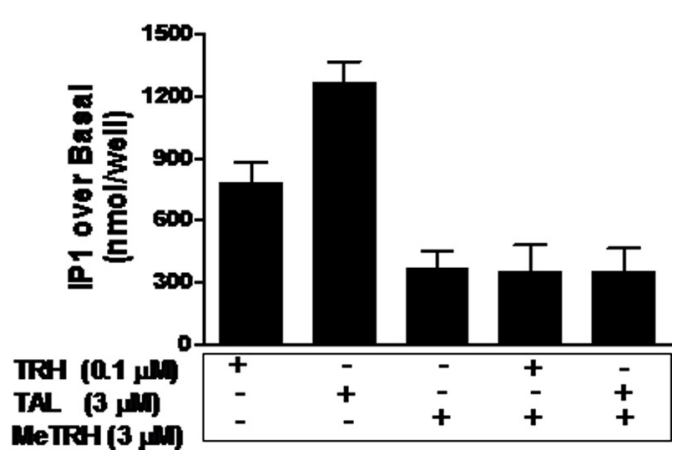

(B) MeTRH inhibits IP1 formation stimulated by TAL and TRH. IP1 production was determined in the presence of TRH $(0.1 \mu \mathrm{M})$, TAL $(3 \mu \mathrm{M})$, MeTRH (3 $\mu \mathrm{M}), \mathrm{TRH}+\mathrm{MeTRH}$, or TAL + MeTRH. The data are expressed as mean \pm SEM performed in duplicate of two experiments. 
partial agonist along with a full agonist. We used a similar experimental design herein to confirm that TAL is a superagonist at TRH-R; MeTRH antagonized IP1 production stimulated by both TRH and TAL (Figure 3B).

Previous reports in rodents showed that TAL displayed more activity in stimulating CNS effects than TRH (Suzuki et al., 1990; Brown, 1999). TAL may have similar CNS effects in humans (Gary et al., 2003; Khomane et al., 2011). The differences in the activities of TAL and TRH in the CNS have been attributed to the higher stability in blood and increased penetration of the blood-brain barrier of TAL compared to TRH. Although this is likely true, our new findings of the signaling efficacy of TAL at TRH-R suggest that the higher intrinsic efficacy of TAL may be contributing to its CNS activity in humans also.

\section{REFERENCES}

Asai, H., Asahi, T., Yamamura, M., Yamauchi-Kohno, R., and Saito, A. (2005). Lack of behavioral tolerance by repeated treatment with taltirelin hydrate, a thyrotropinreleasing hormone analog, in rats. Pharmacol. Biochem. Behav. 82, 646-651.

Asai, H., Kinoshita, K., Yamamura, M., and Matsuoka, Y. (1999). Diversity of thyrotropin-releasing hormone receptors in the pituitary and discrete brain regions of rats. Jpn. J. Pharmacol. 79, 313-317.

Brown, W. (1999). Taltirelin. Tanabe Seiyaku. IDrugs 2, 1059-1068.

Duthie, S. M., Taylor, P. L., and Eidne, K. A. (1993). Characterization of the mouse thyrotrophin-releasing hormone receptor gene: an exon corresponds to a deletion in the rat cDNA. J. Mol. Endocrinol. 11, 141-149.

Engel, S., Neumann, S., Kaur, N., Monga, V., Jain, R., Northup, J., et al. (2006). Low affinity analogs of thyrotropin-releasing hormone are super-agonists. J. Biol. Chem. 281, 13103-13109.

Gary, K. A., Sevarino, K. A., Yarbrough, G. G., Prange, A. J. Jr., and Winokur, A. (2003). The thyrotropin-releasing hormone
(TRH) hypothesis of homeostatic regulation: implications for TRHbased therapeutics. J. Pharmacol. Exp. Ther. 305, 410-416.

Gershengorn, M. C. (1986). Mechanism of thyrotropin releasing hormone stimulation of pituitary hormone secretion. Аnnu. Rev. Physiol. 48 515-526.

Horita, A. (1998). An update on the CNS actions of TRH and its analogs. Life Sci. 62, 1443-1448.

Horita, A., Carino, M. A., and Lai, H. (1986). Pharmacology of thyrotropin-releasing hormone. Annu. Rev. Pharmacol. Toxicol. 26 311-332.

Khomane, K. S., Meena, C. L., Jain, R., and Bansal, A. K. (2011). Novel thyrotropin-releasing hormone analogs: a patent review. Expert Opin. Ther. Pat. 21, 16731691.

Kinoshita, K., Yamamura, M., and Sugihara, J. (1997). Distribution of thyrotropin-releasing hormone $(\mathrm{TRH})$ receptors in the brain of the ataxic mutant mouse, rolling mouse Nagoya. Biol. Pharm. Bull. 20, 86-87.

Matre, V., Karlsen, H. E., Wright, M. S., Lundell, I., Fjeldheim, A. K., Gabrielsen, O. S., et al. (1993). Molecular cloning of a functional

In summary, we have described characterization of the pharmacology of TAL at TRH-R. Most importantly, we showed that TAL is a superagonist when signaling at TRH-R via the $G_{q / 11}$ protein-phospholipase C-phosphatidylinositol-4,5-bisphosphateinositol-1,4,5-trisphosphate-calcium pathway. We suggest the superagonism exhibited by TAL may, in addition to its relative metabolic stability and ability to cross the blood-brain barrier, explain its higher activity in mediating CNS effects in humans compared to TRH.

\section{ACKNOWLEDGMENTS}

This work was supported by the Intramural Research Program of the National Institutes of Diabetes and Digestive and Kidney Diseases, US National Institutes of Health (1 Z01 DK011006).

human thyrotropin-releasing hormone receptor. Biochem. Biophys. Res. Commun. 195, 179-185.

O’Dowd, B. F., Lee, D. K., Huang, W., Nguyen, T., Cheng, R., Liu, Y., et al. (2000). TRH-R2 exhibits similar binding but distinct regulation and anatomic distribution compared to TRH-R1. Mol. Endocrinol. 14, 183-193.

Sun, Y., Lu, X., and Gershengorn, M. C. (2003). Thyrotropin-releasing hormone receptors - similarities and differences. J. Mol. Endocrinol. 30, 87-97.

Suzuki, M., Sugano, H., Matsumoto, K., Yamamura, M., and Ishida, R. (1990). Synthesis and central nervous system actions of thyrotropin-releasing hormone analogues containing a dihydroorotic acid moiety. J. Med. Chem 33, 2130-2137.

Yamamura, M., Kinoshita, K., Nakagawa, H., and Ishida, R. (1991). Pharmacological study of TA-0910, a new thyrotropin-releasing hormone (TRH) analog (III): inhibition of pentobarbital anesthesia. Jpn. J. Pharmacol. 55, 69-80.

Yamamura, M., Suzuki, M., and Matsumoto, K. (1997). Synthesis and pharmacological action of TRH analog peptide (taltirelin). Nihon
Yakurigaku Zasshi 110(Suppl. 1), P33-P38.

Conflict of Interest Statement: The authors declare that the research was conducted in the absence of any commercial or financial relationships that could be construed as a potential conflict of interest.

Received: 10 July 2012; paper pending published: 20 August 2012; accepted: 20 September 2012; published online: 09 October 2012.

Citation: Thirunarayanan N, Raaka BM and Gershengorn MC (2012) Taltirelin is a superagonist at the human thyrotropin-releasing hormone receptor. Front. Endocrin. 3:120. doi: 10.3389/ fendo.2012.00120

This article was submitted to Frontiers in Neuroendocrine Science, a specialty of Frontiers in Endocrinology.

Copyright (c) 2012 Thirunarayanan, Raaka and Gershengorn. This is an openaccess article distributed under the terms of the Creative Commons Attribution License, which permits use, distribution and reproduction in other forums, provided the original authors and source are credited and subject to any copyright notices concerning any third-party graphics etc. 